\title{
Prevalence and risk factors for latex allergy: a cross sectional study in a United Kingdom hospital
}

\author{
J Smedley, A Jury, H Bendall, A Frew, D Coggon
}

MRC Environmental Epidemiology Unit

J Smedley

H Bendall

D Coggon

Occupational Health and Safety Service, Southampton University Hospital NHS Trust

A Jury

Department of Medicine, University of Southampton, Southampton General Hospital,

Southampton

S016 6YD, UK

A Frew

Correspondence to: Dr Julia Smedley, MRC Environmental Epidemiology Unit, Southampton General Hospital, Southampton S016 6YD, UK. Telephone 0044 1703 777624; email jcs@mrc.soton.ac.uk

Accepted 13 August 1999

\begin{abstract}
Objectives-To determine the prevalence and risk factors for symptoms related to gloves, and the relation between symptoms and immunological evidence of type 1 hypersensitivity to latex in a United Kingdom health care setting.

Methods-A cross sectional survey was carried out among 773 employees at a British hospital. A self administered questionnaire was used to collect information about symptoms related to gloves and associated risk factors in a sample of hospital staff who were likely to use gloves at work. All of those who reported symptoms suggestive of type 1 hypersensitivity were invited for skin prick testing and measurement of specific IgE to latex (RAST).

Results-Among the 372 responders, symptoms related to gloves were common, $49 \%$ reported redness or itching of the hands, $14 \%$ reported urticaria, and $6 \%$ reported chest tightness. However, the frequency of positive skin prick tests and RASTs was surprisingly low (only two subjects tested positive).

Conclusions-These findings indicate the need for caution in the interpretation of symptoms related to gloves even when they seem to suggest type 1 hypersensitivity.

(Occup Environ Med 1999;56:833-836)
\end{abstract}

Keywords: latex; occupational disease; healthcare workers

Type I hypersensitivity to latex has increasingly been recognised as an occupational health problem over the past 15 years, particularly among healthcare workers. ${ }^{1-4}$ Manifestations include urticaria, ${ }^{15}$ rhinoconjunctivitis, ${ }^{1}$ asthma, ${ }^{34}$ and more rarely anaphylaxis. ${ }^{67}$ The apparent rise in incidence has been associated with a growth in the use of rubber gloves to protect against blood borne infections, ${ }^{8}$ although it is not clear to what extent different aspects of glove use influence development of the disorder. Possible risk factors include the duration of wearing gloves, ${ }^{9} 10$ the frequency of changing gloves, ${ }^{11} 12$ whether the gloves are powdered, ${ }^{8}$ and the purity of the rubber from which the gloves are made. ${ }^{8}$ Also, risk may be higher in atopic people. ${ }^{11-16}$ To manage the problem effectively we need better information about the frequency and determinants of latex hypersensitivity so that preventive measures can be optimised and appropriate health surveillance put in place.

Several epidemiological studies have considered these issues, but few data are available from the United Kingdom, and it is possible that risks vary between countries because of differences in patterns of glove use. We therefore carried out a cross sectional survey of latex hypersensitivity and its association with potential risk factors at a British hospital

\section{Method}

The study was conducted at Southampton University Hospitals NHS Trust and focused on staff who were likely often to use latex gloves in the course of their work. From the hospital's personnel records we selected all theatre nurses, operating department professionals, surgeons, and anaesthetists, and also for comparison, nurses in the infectious disease unit and outpatient departments where exposure was expected to be lower. Each subject was sent a short postal questionnaire which asked about job history, use of latex gloves at work, other possible risk factors for latex allergy, and about symptoms associated with glove use. Non-responders were sent a single reminder.

Subjects who reported ever having immediate nettle rash (urticaria) on the hands or wrists, puffiness around the eyes or mouth, chest tightness, wheeze, or anaphylaxis in relation to wearing latex gloves were considered to have symptoms suggestive of type I hypersensitivity to latex. These and a random sample of asymptomatic subjects were invited to undergo skin prick testing and measurement of specific IgE to latex.

Skin prick testing was carried out by a nurse (AJ) who was blind to the history of symptoms of the subject. Tests were performed according to a standard protocol; one drop of each test solution was applied to the volar aspect of the forearm, and the skin was punctured through the drop with a standard skin test needle. The test battery included common inhaled allergens (cat fur, house dust mite, and grass pollens: Bencard), and both positive (histamine) and negative (saline) control solutions. Two methods were used to test for latex sensitivity. Firstly, fragments of latex and vinyl gloves were applied directly to the skin of the forearm and a prick was administered through the glove fragment. Secondly, starch suspension was prepared by washing out the inside of latex and vinyl gloves respectively with saline, and used in the same way as standard skin prick 
Table 1 Response rate according to occupational group

\begin{tabular}{llc}
\hline Occupational group & $\begin{array}{l}\text { Questionnaires } \\
\text { posted } \\
n\end{array}$ & $\begin{array}{l}\text { Replies } \\
n(\%)\end{array}$ \\
\hline $\begin{array}{l}\text { Surgeons and anaesthetists } \\
\text { Theatre nurses and operating department professionals }\end{array}$ & 316 & $143(45)$ \\
$\begin{array}{l}\text { Others } \\
\begin{array}{l}\text { Infectious diseases and outpatient nurses } \\
\text { Total }\end{array}\end{array}$ & 1323 & $171(53)$ \\
\hline
\end{tabular}

Table 2 Prevalence of symptoms during or immediately after the use of latex gloves

\begin{tabular}{|c|c|c|c|c|}
\hline \multirow[b]{2}{*}{ Symptom } & \multicolumn{2}{|c|}{ Lifetime } & \multicolumn{2}{|c|}{ Past month } \\
\hline & $\begin{array}{l}\text { Cases } \\
n\end{array}$ & $\begin{array}{l}\text { Prevalence } \\
\%^{\star}\end{array}$ & $\begin{array}{l}\text { Cases } \\
n\end{array}$ & $\begin{array}{l}\text { Prevalence } \\
\% \star\end{array}$ \\
\hline Redness or itching of the hands or wrists & 178 & 49.4 & 95 & 26.7 \\
\hline Eye soreness or watering & 70 & 19.9 & 38 & 10.8 \\
\hline Puffiness around the eyes or mouth & 31 & 9.1 & 15 & 4.4 \\
\hline Urticaria (nettle rash) & 47 & 13.8 & 28 & 8.2 \\
\hline Chest tightness or wheeze & 22 & 6.4 & 8 & 2.3 \\
\hline
\end{tabular}

*Percentage of those who answered the question. Data were missing for up to 32 subjects. The symptom categories in this table are not mutually exclusive. 86 Subjects reported one or more symptoms in their lifetime, and 41 reported more than one symptom in the past month.

Table 3 Risk of symptoms suggestive of type 1 latex hypersensitivity according to atopic history and occupation

\begin{tabular}{|c|c|c|c|c|}
\hline \multirow[b]{2}{*}{ Risk factor } & \multicolumn{2}{|c|}{ Lifetime prevalence } & \multicolumn{2}{|c|}{ Prevalence in past month } \\
\hline & $\begin{array}{l}\text { Cases } \\
n\end{array}$ & ${ }^{\star} R R(95 \% C I)$ & $\begin{array}{l}\text { Cases } \\
n\end{array}$ & ${ }^{\star} R R(95 \% C I)$ \\
\hline \multicolumn{5}{|c|}{ Atopic symptoms before first job in healthcare: } \\
\hline Never & 41 & 1.0 (baseline) & 20 & 1.0 (baseline) \\
\hline Ever & 24 & $1.4(0.9$ to 2.1$)$ & 16 & $1.9(1.1$ to 3.5$)$ \\
\hline \multicolumn{5}{|l|}{ Occupation: } \\
\hline $\begin{array}{l}\text { Nurses in infectious disease unit or } \\
\text { outpatient department }\end{array}$ & 7 & 1.0 (baseline) & 4 & 1.0 (baseline) \\
\hline Surgeon & 13 & $0.3(0.5$ to 3.2$)$ & 5 & $0.8(0.2$ to 2.7$)$ \\
\hline Anaesthetist & 6 & $1.7(0.6$ to 4.8$)$ & 4 & $1.6(0.4$ to 6.5$)$ \\
\hline Theatre nurse & 29 & $2.6(1.2$ to 5.4$)$ & 18 & $2.8(1.0$ to 7.7$)$ \\
\hline Operating department professional & 10 & $5.4(2.4$ to 12.4$)$ & 7 & $5.6(1.7$ to 18.7$)$ \\
\hline
\end{tabular}

^Risk estimates are mutually adjusted as well as being adjusted for age (in three strata) and sex. Data were missing for up to 102 subjects.

solutions. A test was regarded as positive if after 15 minutes it had produced a wheal with diameter at least $3 \mathrm{~mm}$ greater than that produced by the negative control. Specific IgE to latex was measured by a standard radioallergosorbent (RAST) assay with Hevia brasiliensis antigen supplied by Diagnostic Products Corporation (Ala STAT).

Associations between symptoms and risk factors were analysed with a log-logistic regression model, and risk estimates were expressed as prevalence rate ratios (RRs) with $95 \%$ confidence intervals $(95 \% \mathrm{CIs})$.

\section{Results}

A total of 773 subjects were selected from the personnel records, of whom $372(48 \%)$ replied to the questionnaire. Table 1 shows the differential response rate in each of the broad occupational categories. The ages of the responders ranged from 19 to 64 years (mean 40 years) and $67 \%$ of them were women. Fifty six (15\%) reported that they donned $\geqslant 20$ pairs of latex gloves in an average working day, and 178 (48\%) 5-19 pairs. Altogether 177 (48\%) indicated that they regularly wore gloves for $>1$ hour in total over a working day. The most frequent and prolonged use of gloves was by theatre nurses and operating department professionals.
Table 4 Risk of symptoms during the past month suggestive of type 1 latex hypersensitivity according to exposure to latex gloves in the current job

\begin{tabular}{|c|c|c|}
\hline Risk factor & $\begin{array}{l}\text { Cases } \\
n\end{array}$ & ${ }^{\star} R R(95 \% C I)$ \\
\hline \multicolumn{3}{|c|}{ Pairs of gloves used in an average day (n): } \\
\hline $1-4$ & 3 & 1.0 (baseline) \\
\hline $5-19$ & 24 & $2.6(0.8$ to 8.4$)$ \\
\hline$\geqslant 20$ & 8 & $3.5(0.9$ to 13.0$)$ \\
\hline \multicolumn{3}{|c|}{ Wearing gloves for $>1 \mathrm{~h}$ : } \\
\hline No & 13 & 1.0 (baseline) \\
\hline Yes & 22 & $0.8(0.3$ to 1.8$)$ \\
\hline \multicolumn{3}{|c|}{$\begin{array}{l}\text { Working for }>1 \mathrm{~h} \text { in a room where others are wearing latex } \\
\text { gloves: }\end{array}$} \\
\hline No & 9 & 1.0 (baseline) \\
\hline Yes & 26 & $1.5(0.6$ to 4.0$)$ \\
\hline
\end{tabular}

*All risk estimates were mutually adjusted as well as being adjusted for age (in three strata), sex, atopic history before entry to work in health care and occupation.

Data were missing for 127 subjects.

Table 2 shows the lifetime and 1 month prevalence of symptoms associated with the use of latex gloves. The most common complaints were redness or itching of the hands or wrists and eye soreness or watering, but symptoms more strongly suggestive of type I hypersensitivity - such as puffiness around the eyes or mouth, nettle rash, and chest tightness or wheeze-were not infrequent. Of the 47 subjects who reported ever having nettle rash, five had also experienced chest tightness or wheeze when using gloves. Only one subject reported anaphylaxis in relation to glove use, and this had not occurred during the past month. Ten subjects said that they had had chest tightness or wheeze when in the same room as others using latex gloves. Sixty three subjects ( $15 \%$ of responders) had at some time changed their use of gloves because of a health problem related to latex. Three subjects $(0.8 \%$ of responders) had changed job because of a health problem related to latex.

Table 3 shows the association between symptoms suggestive of type I hypersensitivity to latex and occupation and atopic history. History of atopy was defined as a report of any of the following: dryness or cracking of the hands; chest tightness; wheeze or persistent blocked or runny nose in the absence of a cold. Type 1 symptoms in the past month were significantly more common in subjects who had experienced atopic symptoms before they began work in health care (RR 1.9, 95\% CI 1.1 to 3.5), but the association of atopy with the lifetime prevalence of symptoms related to latex was weaker. After adjustment for age, sex, and atopy, there was marked variation in the prevalence of symptoms between occupational groups. In particular, the risk of symptoms, both recent and over a working lifetime, was relatively low in surgeons and anaesthetists, and much higher in theatre nurses and operating department professionals.

Table 4 summarises the relation between symptoms in the past month and glove usage. Risk tended to increase with the number of gloves used in an average working day, but the trend just failed to reach significance $(p=0.06)$. By contrast, there was no association with the use of gloves for $>1$ hour in total. Nor was there a clear increase of risk from working in a room where others were wearing latex gloves. 
One hundred and six subjects (53 symptomatic and 53 without symptoms) were invited to undergo skin prick and RAST testing, but 19 had left the Trust since answering the questionnaire and could not be contacted, and 28 declined. Among the 59 (33 with symptoms) who were tested, one subject with symptoms and one without were positive on both tests and all other results were negative.

\section{Discussion}

This survey of hospital staff found a high prevalence of symptoms related to the use of latex gloves, but demonstrable type I hypersensitivity to latex was comparatively rare.

The study sample was chosen to include occupational groups who regularly wore latex gloves, and the frequency of prolonged and frequent use was especially high among nonmedical theatre staff. The response rate to the questionnaire $(48 \%)$ was relatively low, and it is possible that subjects with symptoms were more inclined to respond than those without. Nevertheless, even when allowance is made for this possible bias, symptoms associated with glove use were remarkably common.

The most frequent symptom was redness or itching of the hands, which was reported to have occurred at some time by almost half of the responders. Other studies have also found high rates of such symptoms in healthcare staff, with lifetime prevalences ranging from $28 \%-57 \% .^{9}{ }^{13} 17$ They could arise from irritant contact dermatitis and from allergic dermatitis provoked by accelerators in rubber, as well as from possible type IV hypersensitivity to latex.

Of the symptoms suggestive of type I hypersensitivity to latex, urticaria after the use of gloves was the most common. The lifetime prevalence of $13.8 \%$ is consistent with rates of $8 \%-16 \%$ reported from other surveys. ${ }^{8} 91318$ On the other hand, puffiness around the eyes or mouth related to gloves $(9.1 \%)$ and wheeze or chest tightness $(6.4 \%)$ were reported rather more often than in earlier studies. ${ }^{8} 9131417-19$ Only one subject described anaphylaxis relative to glove use, but life threatening symptoms of this sort may be underascertained in cross sectional surveys because they cause people to leave their jobs.

Given the high prevalence of symptoms related to gloves, the frequency of positive skin prick and RAST tests to latex was surprisingly low. Among the 33 subjects with symptoms and 26 without, who were tested, only two were positive and one of these did not have symptoms. In previous European and American studies, the prevalence of skin prick test positivity among healthcare workers has ranged from $2.9 \%-12.1 \% .^{8911} 121519$ We do not think our low rate is attributable to errors in the testing procedure. Standard latex skin test solutions were not commercially available at the time this study was carried out. In clinical practice we have found good concordance between type 1 symptoms and skin prick testing for latex with this technique. Moreover, in this study, skin prick and RAST tests were assessed independently and showed complete concordance. The estimate may have been low because of random sampling variation, but also, two possible sources of bias must be considered. Subjects with severe symptoms from latex sensitivity may have been selected out of the workforce so that they were excluded from our cross sectional analysis; and subjects with symptoms which they perceived might threaten their careers may have declined to participate. The findings are, however, an indication for caution in the interpretation of reported symptoms, even when they seem strongly suggestive of type I hypersensitivity.

Because of this problem, it is difficult to draw strong conclusions from the analysis of risk factors for symptoms related to gloves. The most important risk factors identified were work as a theatre nurse or operating department professional, and frequent changes of gloves. However, these associations may have been influenced by differences in people's threshold for reporting symptoms, and may reflect pathology other than type I hypersensitivity. The low response rate to the questionnaire would not have had an important effect on these associations unless the risk factors differentially influenced the tendency to reply in those with symptoms.

Although the prevalence of confirmed type I hypersensitivity to latex in this study was relatively low, it can have serious consequences, particularly if it occurs in a highly trained member of staff and necessitates a change of career with retraining. Thus, there are strong grounds for trying to minimise its occurrence by the use of non-powdered gloves with low levels of protein residue, particularly in areas like operating theatres. At the same time, further research is needed, with large samples of subjects and good response rates, to confirm that such policies produce the benefits that would be expected.

Our findings provide no justification for selective exclusion of potential employees at pre-employment health assessment because of a risk of latex allergy, except in some cases where there is confirmed pre-existing type I hypersensitivity. Nor do they suggest that highly intensive health surveillance for staff who use latex gloves is justified. The aim should be to detect the few workers with more severe or deteriorating symptoms at an early stage so that they can be investigated more thoroughly. Thus education of healthcare workers to report symptoms related to gloves early is as important as conventional health surveillance.

1 Carrillo T, Cuevas M, Munoz T, et al. Contact urticaria and rhinitis from latex surgical gloves. Contact Dermatitis rhinitis from $1986 ; 15: 69-72$.

2 Marcos C, Lázaro M, Fraj J, et al. Occupational asthma due to latex surgical gloves. Ann Allergy 1991;67:319-23.

3 Vandenplas O, Delwiche J-P, Sibille Y. Occupational asthma due to latex in a hospital administrative employee. Thorax 1996;51:452-3

4 Vandenplas O. Occupational asthma caused by natural rubber latex. Eur Respir f 1995;8:1957-65.

5 Nutter AF. Contact urticaria to rubber. Br f Dermatol 1979; 101:597.

6 Ownby DR, Tomlanovich M, Sammons N, et al. Anaphylaxis associated with latex allergy during barium enema laxis associated with latex allergy during barium en

7 Slater JE. Rubber anaphylaxis. N Engl f Med. 1989;320: Slater JE.
$1126-30$. 
8 Vandenplas O, Delwiche J-P, Evrard G, et al. Prevalence of occupational asthma due to latex among hospital personnel. Am 7 Respir Crit Care Med 1995;151:54-60.

9 De Groot H, de Jong NW, Duijster E, et al. Prevalence of natural rubber latex allergy (type 1 and type IV) in laboratory workers in the Netherlands. Contact Dermatitis 1998;38:159-63.

10 Kujala VM, Reijula KE. Glove-induced dermal and respiratory symptoms among health care workers in one Finnish hospital. Am F Ind Med 1995;28:89-98.

11 Turjanmaa K. Incidence of immediate allergy to latex gloves in hospital personnel. Contact Dermatitis 1987;17:270-5.

12 Liss GM, Sussman GL, Deal K, et al. Latex allergy: epidemiological study of 1351 hospital workers. Оссир Environ Med 1997;54:335-42.

13 Grzybowski, M, Ownby DR, Peyser PA, et al. The prevalence of anti-latex IgE antibodies among registered nurses. F Allergy Clin Immunol 1996;98:535-44.
14 Hunt LW, Fransway AF, Reed CE, et al. An epidemic of occupational allergy to latex involving health care workers. f Occup Environ Med 1995;37:1204-9.

15 Arellano R, Bradley J, Sussman G. Prevalence of latex sensitization among hospital physicians occupationally exposed to latex gloves. Anesthesiology 1992;77:905-8.

16 Lai C-C, Yan D-C, Yu J, et al. Latex allergy in hospital employees. F Formos Med Assoc 1997;96:266-71.

17 Katelaris CH, Widmer RP, Lazarus RM. Prevalence of latex allergy in a dental school. Med f Aust 1996;164: latex all $711-4$.

18 Field EA. Atopy and other risk factors for UK dentists reporting an adverse reaction to latex gloves. Contact Dermatitis 1998;38:132-6.

19 Safadi GS, Corey EC, Taylor JS, et al. Latex hypersensitivity in emergency medical service providers. Ann Allergy Asthma Immunol 1996;77:39-42.

\section{Correspondence and editorials}

Occupational and Environmental Medicine welcomes correspondence relating to any of the material appearing in the journal. Results from preliminary or small scale studies may also be published in the correspondence column if this seems appropriate. Letters should be not more than 500 words in length and contain a minimum of references. Tables and figures should be kept to an absolute minimum. Letters are accepted on the understanding that they be subject to editorial revision and shortening.

The journal also publishes editorials which are normally specially commissioned. The Editor welcomes suggestions regarding suitable topics; those wishing to submit an editorial, however, should do so only after discussion with the Editor. 